\title{
Predicting Volcanic Eruptions
}

Important advances in the prediction of volcanic eruptions, based on recent work on Mount St. Helens, have been summarized recently by D.A. Swanson, T.J. Casadevall, D. Dzurisin, C.G. Newhall and C.S. Weaver, of the USGS and S.D. Malone of the University of Washington (Science, September 30,1983$)$. They report that 13 eruptions between June 1980 and December 1982 were predicted from tens of minutes to a few hours in advance. The last 7 of these eruptions, from mid-April 1981 onwards, were predicted between 3 days and 3 weeks in advance.

The authors point out that a prediction of volcanic eruption should state clearly the location on the volcano where the activity will occur, a reasonably short period of time within which the eruption is expected, and the type and magnitude of eruption (e.g. explosive or non-explosive, large or small). An ideal prediction should also include a statement of the likelihood of each part of the prediction. Forecasts, on the other hand, are statements concerning future eruptive activity that cannot be as precise as a prediction. For example, stratigraphical studies between 1960 and 1975 showed that Mount St. Helens had erupted frequently and explosively in the recent geological past, and the researchers then suggested that the Mount "will erupt again, perhaps before the end of this century." Another type of forecast is made when "restlessness" of a volcano is recognized, but not well enough understood to permit a formal prediction.

A prediction must be understandable if it is to be useful for non-scientists, and it may be necessary to balance the public official's need to know against a volcanologist's need for more data. Predictions for Mount St. Helens are not released until precursory data show a well-defined trend. Relatively long-term predictions, based mainly on geodetic measurements of ground deformation, are issued several days to 2-4 weeks in advance, and relatively short-term predictions, based primarily on telemetered seismic and tilt data, are made within 1-2 days of the anticipated eruption.

The single most important source of data for short-term predictions is seismic monitoring. At Mount St. Helens seismic precursors are associated with deep or distant earthquakes, with shallow earthquakes located under the dome at a depth of less than $3 \mathrm{~km}$, and with surface events such as rock falls and energetic gas bursts. Shallow volcanic earthquakes were observed between 1980 and 1982 in increasing numbers several days to $1-2$ weeks before each dome-building eruption.

Records of change in the inclination of the ground surface using electronic tilt meters have been particularly useful for short-term predictions. Indeed tilt measurements are one of the most reliable methods for predicting eruptions several days to 2-4 weeks in advance. From June 1981 to August 1982, tilting of the crater floor began several weeks before each of six eruptions. The tilting accelerated sharply for several days and then abruptly changed direction a few minutes to days before the extrusion began. Each episode of uplift was caused by the intrusion of magma into the lava dome from a shallow source, causing the dome to inflate and eventually rupture. Release of magma pressure and increased surface loading by magma added to the dome combined to cause subsidence just prior to extrusion.

The best basis for long-term predictions has been measurement of cracks and thrust faults, for these measurements present the most consistent patterns, can be made during periods of poor weather and visibility, and require only simple equipment such as a steel tape and few personnel.

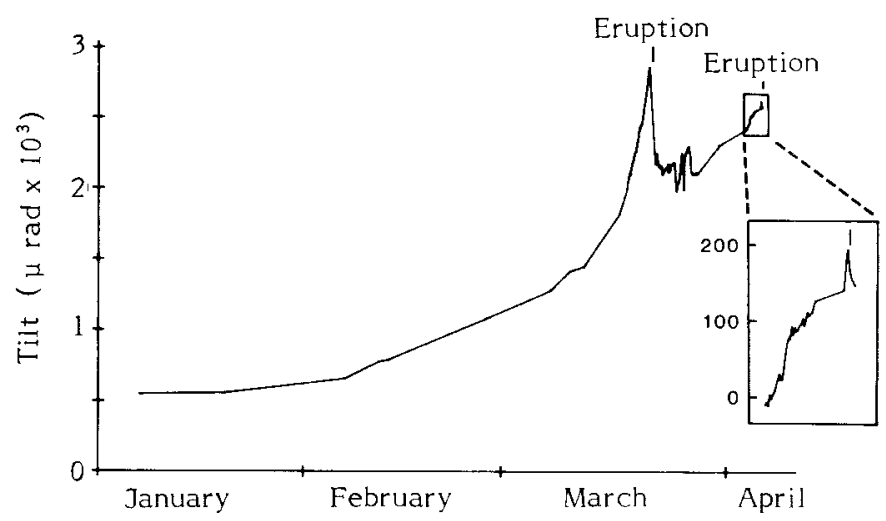

Figure 1: Tiltmeter data, Mount St. Helens, 1982, showing sharply accelerating radial uplift followed by rapid subsidence before the eruptions (after Dzurisin et al., Science, September 30, 1983, p. 1382).

Also useful has been the monitoring of emission rates of $\mathrm{SO}_{2}$ and $\mathrm{CO}_{2}$ in the plume of the volcano. Changes in these rates were useful in anticipating eruptions in August 1980, when $\mathrm{CO}_{2}$ decreased, and June 1981, when $\mathrm{SO}_{2}$ increased. Emission rates were at their peak during July and August 1980, decreased rapidly in late 1980 and have remained low and decreased slightly during 1981 and 1982. These patterns suggest steady outgassing of a single batch of magma to which there have been no significant additions since mid1980.

The record of prediction from 1980-1982 has thus been extremely successful, and no incorrect predictions or "false alarms" have been issued. The authors are confident that future eruptions at Mount St. Helens can also be predicted, provided that the style of repeated, short-lived doming events continues, and prolonged bad weather neither prevents access to the crater nor causes a loss of telemetry and funding remains adequate. However, improvements are needed in the ability to discriminate between predominantly explosive and predominantly non-explosive eruptions as well as in the ability to anticipate the duration and end of an eruption. The authors believe that the predictive methods used at Mount St. Helens can be applied to other volcanoes that erupt lava of predominantly andesitic and dacitic composition. 


\section{International Permafrost Association Formed}

A new scientific association was formed at the 4th International Conference on Permafrost held in Fairbanks, Alaska, during July 1983. Participants at several of these conferences had discussed the possibility of formalizing their meetings. At the 1978 conference in Edmonton, Alberta, a request was made to the Canadian delegation to explore the possibility of forming an international association. Accordingly, the Canadian delegation to the Fairbanks conference presented a proposal to the delegations from the U.S.A., U.S.S.R. and China.

The proposal to establish the International Permafrost Association included a Canadian offer to support a secretariat for the first five years in Canada under the direction of Prof. J.R. Mackay of the University of British Columbia, who would serve as the first Secretary General. This was accepted unanimously and the new association was formed, with an invitation extended to other countries to join. Academician P.I. Melnikov of the Moscow-based Scientific Council for Cryology is the new President, and Dr. T.L. Péwé (U.S.A.) and Dr. K. Flaate (Norway) are Vice-Presidents.

The objective of IPA is to foster the dissemination of knowledge concerning permafrost and to promote cooperation in scientific or engineering work on permafrost. Membership is through national adhering bodies, but in countries where no such group exists, an individual may apply directly to take part in IPA activities. Further information and copies of the constitution and by laws of the new association may be obtained from J.R. Mackay, Secretary General IPA, University of British Columbia, 217-1984 West Mall, Vancouver, B.C., Canada V6T 1 W5.

\section{$\mathrm{CO}_{2}$ and Changing Climate}

The U.S. National Academy of Sciences has recently released a report which concludes that atmospheric $\mathrm{CO}_{2}$ levels are likely to double by late in the next century, causing an increase in global average temperatures, most likely in the range of 1.5 to $3.0^{\circ} \mathrm{C}$. "Once the $\mathrm{CO}_{2}$ content of the atmosphere rises significantly, it is likely to remain elevated for centuries," according to the report. The magnitude and rate of change of such a warming would have "few or no precedents in the earth's recent history," for the entire development of civilization since the last ice age has "taken place in a global climate never more than $1^{\circ} \mathrm{C}$ warmer or colder" than at present. The report admits that predicting future events is always difficult; the models are only as good the information that goes into them, and many of the variables are inherently unpredictable.

A plot of average yearly concentrations of $\mathrm{CO}_{2}$ in the atmosphere from 1958, when good measurements were first taken, to 1981 shows a gradually rising incline from $315 \mathrm{ppm}$ to $340 \mathrm{ppm}$ in one generation. World-wide energy consumption will also increase, though at what rates is a matter for conjecture. Estimates of energy consumption during the next 50 years vary by a factor of two, and the resulting increases in $\mathrm{CO}_{2}$ vary by a factor of three or more. A new model described in the report assigns a range of possible values for various economic and $\mathrm{CO}_{2}$ values, accounting for both uncertainties in economic growth and in the type of fuel used as energy sources. The best guess is that $\mathrm{CO}_{2}$ emissions will grow by $1.6 \%$ annually to the year 2025 and then by about $1 \%$ annually to 2100 , this estimate being somewhat lower than those in earlier studies.

About half the $\mathrm{CO}_{2}$ would be expected to remain in the atmosphere, the rest being dissolved in the ocean. The level of $\mathrm{CO}_{2}$ in the atmosphere would be expected (with a $50 \%$ probability) to double its current concentration sometime between the year 2050 and 2100 . Of course, increasing levels in other gases such as chlorofluorocarbons, nitrous oxide, and methane could also produce greenhouse effects and could be just as important a factor in climatic change as $\mathrm{CO}_{2}$.

All of the climate models discussed in the report predict a significant increase in world-wide temperatures, with greater rises in the polar regions, earlier snow melts and later first snowfalls, less summer soil moisture in some middle and high latitudes of the northern hemisphere, and thinner Arctic and Antarctic ice cover. The impact of lower precipitation on the rich crop areas of the western U.S.A. would be severe.

More speculative are expected changes in sea-level as a result of $\mathrm{CO}_{2}$ warming. Calculations by Roger Revelle show that given a global warming of $3-4^{\circ} \mathrm{C}$, expansion of upper ocean waters and melting of continental ice from Greenland and the Arctic and of ice in high mountains could produce a rise in sea-level of about $70 \mathrm{~cm}$ over the next century, compared to the $15 \mathrm{~cm}$ rise of the past 100 years. Sea-level could therefore rise by about $1-2 \mathrm{~m}$ per hundred years over the next 200-500 years, if portions of the Antarctic icecap were to collapse completely. Sea-level changes of this magnitude would, of course, cause major changes in contours of coastal areas, though the report points out that the Dutch have been successfully living several metres below sea-level for hundreds of years.

Despite the possible seriousness of the projected climate changes, the report adopts a "conservative" stance, believing that "there is reason for caution, not panic." It concludes that uncertainties in both the scientific concepts describing $\mathrm{CO}_{2}$ climate effects and the inherent uncertainty of economic and social variables argue against major changes in policy at this time. The report does not, therefore, support any restrictions on the development of synthetic fuels, for "shifting the fuel mix within fossil fuels is highly unlikely to achieve a reduction of $\mathrm{CO}_{2}$ concentrations by more than a few parts per million by the year 2100 , even if accomplished globally." What is needed instead, says the report, is careful monitoring of $\mathrm{CO}_{2}$ levels and continued scientific attention to the various components of $\mathrm{CO}_{2}$ emissions, atmospheric concentrations, climate changes, and environmental and social impacts and responses. ("Changing Climate", Carbon Dioxide Assessment Committee, National Academy Press, Washington, 1983, 519p).

It is interesting to note that shortly before this report was released, the U.S. Environmental Protection Agency stated its own conclusions that the climate would warm up sooner than predicted in the NRC scenario, with major changes in the $1990 \mathrm{~s}$ and a mean global rise of $2^{\circ} \mathrm{C}$ by 2040 and $5^{\circ} \mathrm{C}$ by 2100 ! 


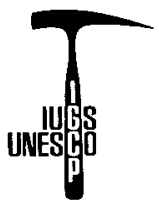

An increasing number of projects of the International Geological Correlation Program are following the guidance of the IGCP Board in encouraging involvement of geoscientists from developing countries. For example, Project 58 on MidCretaceous Events has provided assistance through its secretariat in Uppsala to developing country participants who submit papers on their research to international journals. The secretariat has also been active in launching the new Journal of African Earth Sciences.

Project 61 on Sea-Level Movements is compiling a manual on sea-level research designed to assist researchers in developing countries. This will be a major contribution to international training, for it will present detailed discussions of the use of various shoreline deposits, erosional forms and organic materials for interpreting changes in sea level. Also included will be explanations of the various dangers of misinterpretation and a review of methods for collecting valid samples.

Project 129 on Lateritization Processes has discussed the organization of training programs on lateritic deposits for geologists from developing countries, possibly assisted by Unesco. Project 148 on Quantitative Stratigraphic Correlation Techniques has recently held a four-day short course on new concepts and methods in stratigraphy at the Indian Institute of Technology in Kharagpur, India, designed espe- cially for participants from Bangladesh, China, Burma, Malaysia and Saudi Arabia.

The Phosphorites Project (156) recently held a two-week laboratory workshop in Sydney, Australia, for 14 geologists from countries in SE Asia and the Pacific. An extended course manual of over 1000 pages was compiled for this course. Project 156 participants also took part in a short course on phosphorite rock potential, held in Bangkok in January 1983. Project 193, on the Siluro-Devonian of Latin America is trying to arrange an exchange of personnel and training facilities among Argentina, Bolivia, Brazil, Colombia, Mexico and Venezuela. Argentine experts, for example, have offered to give special courses in biostratigraphy, palaeontology, geology and other subjects for graduates and young researchers from this region.

The IGCP Secretariat and members of the IGCP Board and Scientific Committee have also been actively promoting new projects in Africa, Asia and Latin America. A series of planning meetings held in these regions has resulted in several new projects, and others are in the planning stages. All these activities indicate clearly renewed and growing interest among the IGCP community in expanding its activities to, and involving more scientists from, developing countries.

\section{New International Program to Study Global Change}

It is now generally recognized that the solar-terrestrial system can be viewed as a single living organism whose parts are linked by chemical, physical and biological processes operating on varying scales - in time, from fractions of a second to billion of years, and in space, from less than a centimetre to thousands of kilometres. Over millions of years ecosystems have evolved to produce food, fibre and shelter necessary to sustain human life, but anthropogenic impacts have increased and may well now equal in magnitude the natural processes that control the nature of the global life support system. In order to assess these effects and to understand the system as a whole, a much better understanding is required of the interactions that take place in the space between the Sun and the Earth, in the atmosphere, the hydrosphere, the biosphere, and the lithosphere.

The International Council of Scientific Unions (ICSU) is now considering proposals for a new international program to study global change in the terrestrial environment (geosphere) and the life that inhabits it (biosphere). The study of these changes must transcend the boundaries of specialized scientific disciplines and the limited scope of national scientific endeavours, for these restrictions have been partly responsible for the slow progress in understanding the interactions between oceans and atmosphere, biogeochemical cycles and solar-terrestrial relationships, despite their obvious practical importance. The International Geosphere-
Biosphere Program (IGBP) would therefore link a wide range of sciences in a cooperative global interdisciplinary effort.

One major challenge for IGBP will be to increase our understanding of the causes and effects of climatic change. These appear to be related to a long and complex series of interactions involving among others human and other biological activity, solar radiation, volcanism, ocean circulation, polar ice, and the chemistry and dynamics of the atmosphere itself. On longer time scales, gravitational perturbations of the planets and the moon on the orbit of the Earth are also important, but no single factor is clearly dominant.

Historical, palaeontological and geochemical records gathered from tree-ring data, lake deposits, pollen samples, and ocean and polar ice-cores have provided most of the existing knowledge about past climates and the few insights that we have into the response of the terrestrial environment to internal and external forcing. This interdisciplinary data also relates to past sea temperatures and ice-cover, atmospheric composition, biotic conditions, crustal magnetism, and solar behaviour. But these records will have to be read more extensively and more critically if we are to predict climatic changes and the biological responses to them.

New technologies for remote sensing of the atmosphere, the land, and the sea may be able to revolutionize our grasp of global conditions. SEASAT, for example, demonstrated the 
power of sea-floor mapping from the vantage point of space. Its radar altimeter detected new features such as underwater volcanoes, fracture zones in crustal plates, and regions of ocean crust with unusual gravitational characteristics. Equally great advances have come in the past two decades from orbital sensing of the biosphere aimed at assessing world production of food, fibre and fuel from agricultural crops, forests and range lands. The principle tool here has been infrared mapping, and new microwave techniques have been developed which can penetrate through overcast skies and canopies of vegetation. Orbital measurements of solar radiation fluxes are now providing quantitative data on the influence of solar variations on weather and climate, and ultraviolet imaging from space has literally shown the Earth in a new light.

IGBP would thus have to coordinate global measurements from ground and space, exploiting new technologies, implementing and improving capabilities for data management, and placing proper emphasis on mathematical modelling. It would clearly be a long-range program, taking shape towards the end of this decade and reaching maturity in the 1990s.

ICSU recognizes the importance of linking IGBP with relevant national and international programs such as the World Ocean Circulation Experiment, the International Magnetospheric Study, and the work of the Scientific Committee on the Problems of the Environment dealing with biogeochemical cycles of carbon, nitrogen, sulphur and phosphorus. The theme of biogeochemistry has recently been endorsed by a group of U.S. scientists planning for a NASA program on "Global Habitability." Other programs that would need to be linked in some way to the new IGBP include the International Lithosphere Program, the International Geological Cooperation Program, the World Climate Research Program, and global observing and monitoring programs such as the World Weather Watch, the International Global Oceans Services System, and the Global Environmental Monitoring System.

The first in depth discussion of the IGBP will be at a symposium to be held during the ICSU General Assembly in

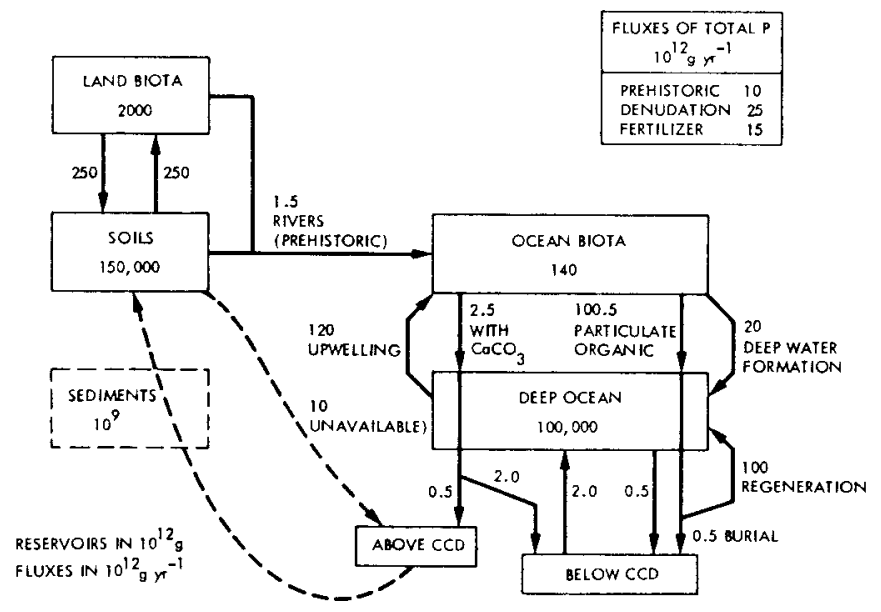

Figure 1: The global cycle of chemically available phosphorous (From M. McElroy, 1983 "Global Change: A Biogeochemical Perspective" - NASA/JPL Publication 83-51).

Ottawa on 25 September 1984. Specially commissioned papers will be prepared and distributed in advance, summarizing developments over the past 25 years and prospects for future research activities. The various constituent unions and bodies of ICSU are invited to participate in this symposium and are encouraged to develop and share their view on the rationale, themes and activities of an international program for the 1990s. Further information may be obtained from Dr. F.W.G. Baker, ICSU Secretariat, 51 Blvd. Montmorency, 75016 Paris, France.

- EPISODES staff from information supplied by ICSU and U.S. National Research Council.

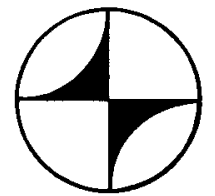

\section{IUGG Urges Global Actions}

The General Assembly of the International Union of Geodesy and Geophysics (IUGG), held in Hamburg, August 25-27, 1983, approved several resolutions of general importance to the geoscience community. One points to the need for cartographic representation of the structure of the Earth's crust and upper mantle, and invites all interested groups to participate actively in the joint project organized by IASPEI and CGMW on mapping these zones.

Another resolution notes that over $95 \%$ of the fresh water on the surface of the earth is in the great ice sheets of Antarctica and Greenland, which may be subject to significant changes in volume leading to widespread effects on sealevel. Although there are no accurate data on changes in the total ice volume, it is now technically practical for the first time to determine by satellite altimetry surface-elevation changes as small as $0.5 \mathrm{~m}$. This would allow a detection of changes in volume in the Antarctic ice sheet of as little as one part in five thousand. The resolution urges that all altimeter-equipped satellites in high latitude orbits should record the surface elevation of the Antarctic and Greenland ice sheets and that these data should be made available to the scientific community.

The General Assembly also endorsed the general objectives of the International Lithosphere Program, and particularly its goal of strengthening the earth sciences and their effective application in developing countries. The resolution supported the move made by IUGS encouraging Unesco to increase budget allocations for ILP scientific meetings and symposia.

Following a statement by a representative of the International Air Transport Association, the IUGG General Assembly called attention to recent incidents involving high-level aircraft entering volcanic ash plumes, the difficulties of ground observers on or near volcanoes providing warning to the pilots in the air, and the potentially disastrous engine failure caused by ash intakes. A resolution was passed urging much closer links between national volcano monitoring agencies and regional air traffic control and meteorological offices. 